HortScience 27(4):310-313. 1992.

\title{
Use of Seed Priming to Bypass Stratification Requirements of Three Aquilegia Species
}

\author{
Terry L. Finnerty ${ }^{1}$, Jayne M. Zajicek ${ }^{2}$, and Mark A. Hussey ${ }^{3}$ \\ Texas A\&M University, College Station, TX 77843 \\ Additional index words. Aquilegia caerulea, A. canadensis, A. hinckleyana, \\ osmoconditioning
}

\begin{abstract}
Seeds of three columbine species, Aquilegia caerulea James, Aquilegia canadensis L., and Aquilegia hinckleyana Munz., were studied to determine if seed priming can be used to enhance or completely bypass stratification. The effect of priming varied among species. Germination percentage of nonstratified, primed seed of A. caerulea was as high as nonprimed stratified seed at the termination of the study. Nonstratified primed seeds of $\boldsymbol{A}$. canadensis did not perform as well as stratified seed, but priming did enhance the germination percentage of stratified seed. Priming had no effect on seed germination-of A. hinckleyana.
\end{abstract}

Seed priming (osmoconditioning) has been shown to increase the rate and uniformity of germination of several vegetable and ornamental species (Atwater, 1980; Bradford, 1986; Brocklehurst and Dearman, 1983; Samfield et al., 1990, 1991). Seed priming has also been shown to overcome thermodormancy in lettuce seeds, allowing seeds to germinate at suboptimal temperatures (Cantliffe et al., 1984). However, to our knowl-

Received for publication 23 Apr. 1991. Accepted for publication 28 Oct. 1991. Texas Agricultural Experiment Journal Article no. 30087. Use of a company or product name does not imply approval or recommendation of the product to the exclusion of others that may also be suitable. We gratefully thank Native Plants, Salt Lake City, Utah, and Containerized Plants, Independence, Texas, for donation of seeds. The cost of publishing this paper was defrayed in part by the payment of page charges. Under postal regulations, this paper therefore must be hereby marked advertisement solely to indicate this fact.

'Graduate Student.

${ }^{2}$ Assistant Professor, Dept. of Horticultural Sciences.

${ }^{3}$ Associate Professor, Dept. of Soil and Crop Sciences. edge, no research has been done to examine the effects of priming on the stratification requirements of ornamental plant species.

Recommended germination treatment for Aquilegia spp. is stratification in moist peatmoss at 3 to $5 \mathrm{C}$ for 2 to 4 weeks before sowing (Ellis et al., 1985b). Stratification can be a problem to producers because of this prolonged pretreatment and because it is not adapted to mechanized production systems (Ball, 1985). Seeds must be separated from the stratification media before they can be sown with automatic seeders, and these seeds may still exhibit undesirable germination characteristics, such as wide variation in time from sowing to emergence and low percentage of total germination (Phillips, 1985). A simple, cost-efficient system is needed to minimize these problems. Combining seed priming with plug production may be one alternative.

The objective of this study was to determine if seed priming can enhance or possibly substitute for stratification to improve the germination of three Aquilegia species.

Seeds of A. caerulea, A. canadensis, and A. hinckleyana, stored at $50 \%$ relative humidity $(\mathrm{RH})$ and $12 \mathrm{C}$, were placed in paper 
Table 1. Analysis of variance for the effects of priming, stratification, and germination temperature on germination of Aquilegia caerulea, A. canadensis. and A. hinckleyana.

\begin{tabular}{|c|c|c|c|c|c|c|c|c|c|c|c|c|c|}
\hline \multirow[b]{3}{*}{ Source } & \multirow[b]{3}{*}{$\mathrm{df}$} & \multicolumn{4}{|c|}{ A. caerulea } & \multicolumn{4}{|c|}{ A. canadensis } & \multicolumn{4}{|c|}{ A. hinckleyana } \\
\hline & & \multicolumn{4}{|c|}{ Days } & \multicolumn{4}{|c|}{ Days } & \multicolumn{4}{|c|}{ Days } \\
\hline & & 7 & 14 & 21 & 28 & 7 & 14 & 21 & 28 & 7 & 14 & 21 & 28 \\
\hline Prim $^{2}$ & 3 & $* *$ & $*$ & NS & $* *$ & NS & ** & $* *$ & $* *$ & NS & NS & NS & NS \\
\hline Temp & 1 & ** & NS & NS & NS & ** & NS & NS & NS & $* *$ & ** & $* *$ & ** \\
\hline Strat & 1 & ** & NS & NS & NS & $* *$ & ** & $* *$ & ** & $* *$ & NS & $*$ & ** \\
\hline Prim $\times$ Temp & 3 & NS & NS & NS & NS & $*$ & NS & NS & NS & NS & NS & NS & NS \\
\hline Prim $\times$ Strat & 3 & $*$ & NS & NS & NS & * & * & $*$ & $*$ & NS & NS & NS & NS \\
\hline Temp $\times$ Strat & 1 & ** & NS & NS & NS & NS & $*$ & * & * & $* *$ & NS & ** & ** \\
\hline
\end{tabular}

${ }^{2}$ Prim = priming duration; Temp = temperature; Strat $=$ stratification. Priming solution was not significant for any of the Aquilegia species and, therefore, is not included in the table.

$\mathrm{NS}, * * *$ Nonsignificant or significant at $P=0.05$ and 0.01 , respectively.

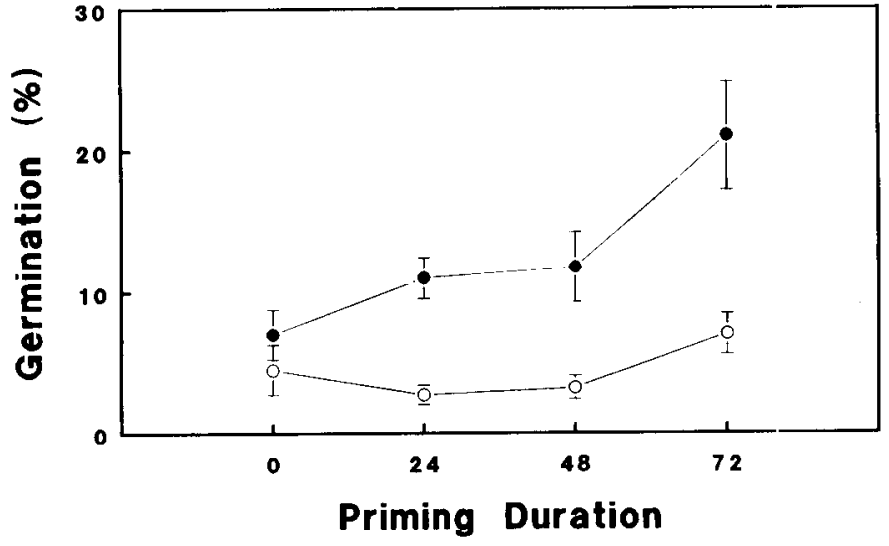

Fig. 1. Germination percentage on day 7 of nonstratified ( $(0)$ and stratified ( $\bullet$ ) Aquilegia caerulea seed as affected by priming duration. Data pooled over all priming solutions and temperatures with three replications ( 50 seeds per replication) per treatment. Vertical bars indicate SE.

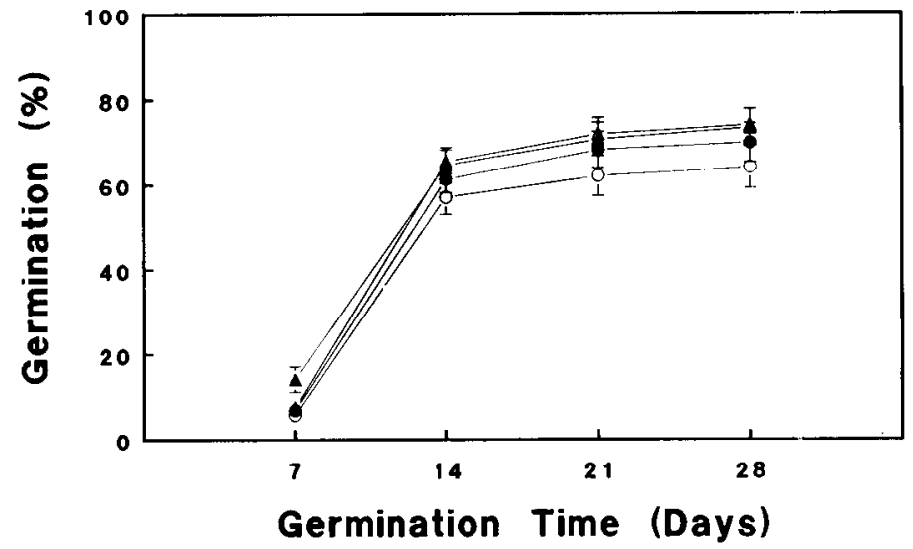

Fig. 2. Germination of Aquilegia caerulea seed primed $24(\bullet), 48(\Delta)$, or $72(\Delta)$ h. Control (o) seeds were not primed. Data pooled over all priming solutions, stratification treatments, and temperatures with three replications ( 50 seeds per replication) per treatment. Vertical bars indicate SE.

mesh bags; these were suspended for 24,48 , or $72 \mathrm{~h}$ in 3-liter plastic bottles containing aerated solutions of double-distilled water $\left(\mathrm{ddH}_{2} \mathrm{O}\right)$ or $50 \mathrm{~mm}$ potassium phosphate buffer $\left(\mathrm{KH}_{2} \mathrm{PO}_{4}+\mathrm{K}_{2} \mathrm{HPO}_{4}, \mathrm{pH} 7.0\right)$ at room temperature $(26 \pm 1 \mathrm{C})$. Priming treatments were modifications of methods previously reported by Samfield et al. (1990, 1991). Each solution was aerated using plastic tubing connected to two 115-V PennPlax (PennPlax Plastic, Garden City, N. Y.) aquarium pumps. After priming, the seeds were removed, rinsed thoroughly in $\mathrm{ddH}_{2} \mathrm{O}$ for 60 see, and airdried at room temperature $(26 \pm 1 \mathrm{C})$ for 24 h. Controls were the nontreated dry seed of each species.
The experiment was conducted as a $2 \times$ $4 \times 2$ factorial in a completely randomized design. After the seeds were air-dried, each treatment, plus controls, was divided into two major groups: 1) nonstratified and 2) stratified at $4 \mathrm{C}$ for 30 days in moist peatmossbased medium (Redi-Earth, W.R. Grace, Cambridge, Mass.). Each group was primed for 0 (control), 24, 48, or $72 \mathrm{~h}$. All seeds were germinated in darkness at 20 or $26 \pm$ $1 \mathrm{C}$, representing the low range of room temperature and normal room temperature, respectively.

Control and nonstratified seeds were germinated immediately after the priming treatments were finished. Each dish contained 50 seeds with three replicate dishes per treatment. Radicle emergence of $\geq 1.0 \mathrm{~mm}$ was scored as germination and was recorded at 24-h intervals for 28 days. Stratified seeds were germinated as above, immediately after the conclusion of the stratification period.

Total germination was calculated at 7, 14, 21 , and 28 days. Analysis of variance was conducted on all data (Steele and Torrie, 1980). The entire study was repeated with similar results from both studies. The data from the second study are presented.

Priming solution did not significantly affect Aguilegia seed germination (data not shown) .

Aquilegia caerulea. Priming duration and stratification significantly affected seed germination of A. caerulea through day 7 , but only priming duration was significant after day 7 (Table 1). At day 7, priming increased the percent germination of stratified seeds, with less effect on nonstratified seeds. The stratified seeds exhibited two to three times the percent germination of nonstratified seeds, regardless of priming duration (Fig. 1).

Priming duration had a small but significant effect on seed germination after day 7 until the termination of the experiment at day 28. About three-fourths of seeds primed for 72 or $48 \mathrm{~h}$ germinated, exceeding the percentage for any other treatment (Fig. 2).

A significant temperature $\mathrm{x}$ stratification interaction was observed on day 7 for $\boldsymbol{A}$. caerulea (Table 1), with mean germination for stratified seed being $12 \%$ and $15 \%$ at 20 and $26 \mathrm{C}$, respectively, and $1 \%$ and $8 \%$ for the nonstratified lots. From day 14 through 28 , there were no significant differences in percent germination between the two temperatures.

Aquilegia canadensis. Priming duration had a significant effect on germination of $A$. canadensis seed from day 14 through 28 (Table 1). The final germination percentage of $61 \%$ was higher than that of the control seeds or those primed for $48 \mathrm{~h}$ and was nearly three times that of those primed for $72 \mathrm{~h}$ (Fig. 3). Priming effects were even more pronounced on stratified seeds. At 28 days, stratified seed primed for $24 \mathrm{~h}$ had a final germination percentage of $69 \%, 30 \%$ higher than for nonstratified seeds primed for $24 \mathrm{~h}$ (Fig. 4). As priming time increased above $24 \mathrm{~h}$, the percent germination decreased (Fig. $4)$.

The interaction of germination temperature and stratification was also significant for 


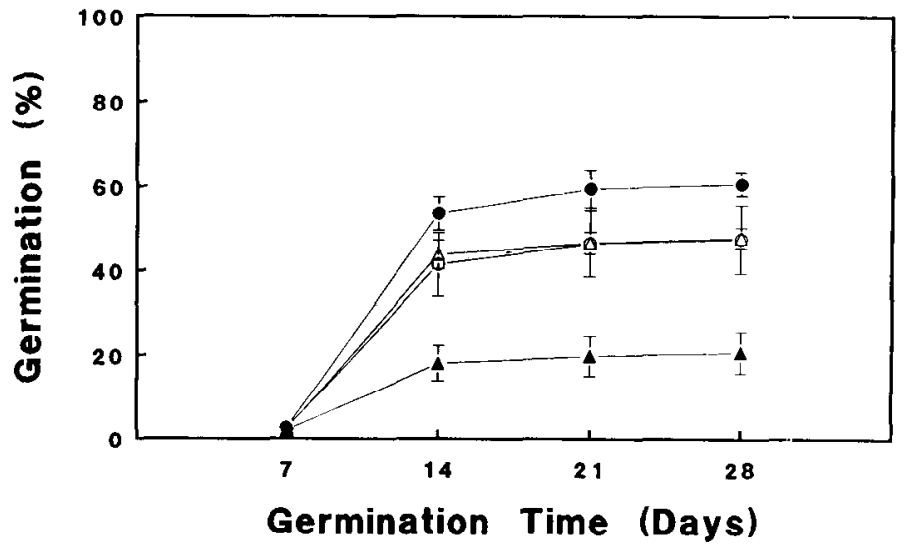

Fig. 3. Germination of Aquilegia canadensis seed primed $24(\bullet), 48(\Delta)$, or $72(\Delta)$ h. Control $(o)$ seeds were not primed. Data pooled over all priming solutions, stratification treatments, and temperatures with three replications (50 seeds per replication) per treatment. Vertical bars indicate SE.

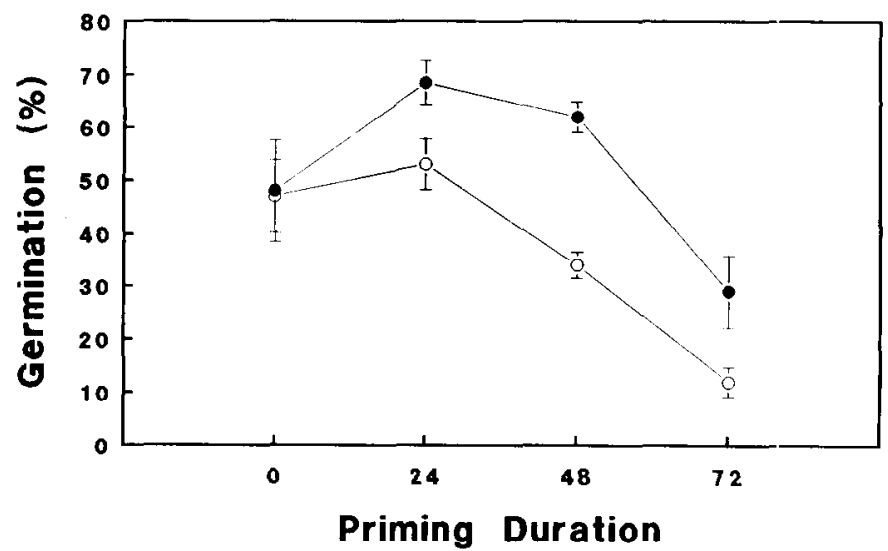

Fig. 4. Germination of nonstratified (o) and stratified (๑) Aquilegia canadensis seed on day 28 (termination of study) as affected by priming duration. Data pooled over all priming solutions and temperatures with three replications (50 seeds per replication) per treatment. Vertical bars indicate SE.

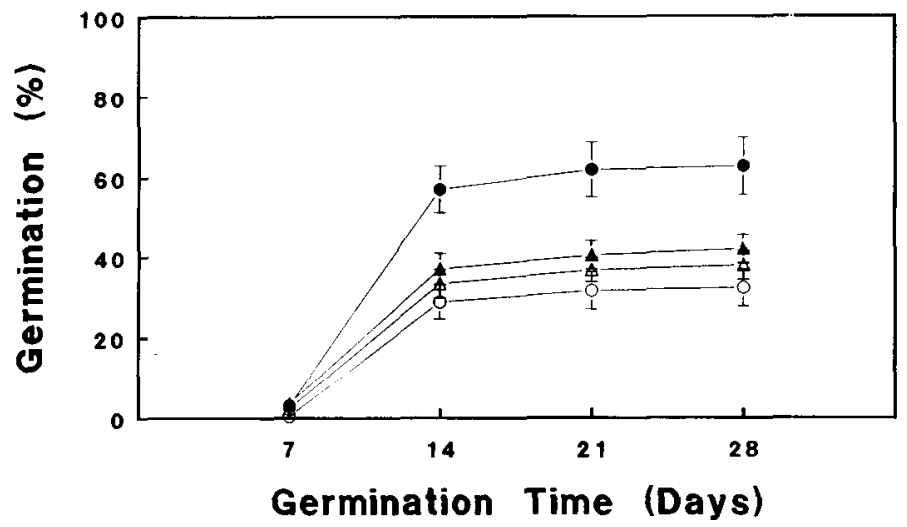

Fig. 5. The effect of germination temperature and stratification on the germination of Aquilegia canadensis seed. Data pooled over all priming solutions and durations with three replications (50 seeds per replication) per treatment. Vertical bars indicate SE. 20C, nonstratified (o); 20C, stratified $(\bullet) ; 26 \mathrm{C}$, nonstratified $(\Delta) ; 26 \mathrm{C}$, stratified $(\Delta)$.

A. canadensis seed germination from day 14 until the end of the experiment at 28 days (Table 1). By the 28th day, stratified seed germinated at $20 \mathrm{C}$ had almost twice the germination percentage $(63 \%)$ compared to nonstratified seeds germinated at either 20 or $26 \mathrm{C}$, and a better germination than stratified seeds germinated at 26C (Fig. 5).

Aquilegia hinckleyana. Priming duration did not have a significant effect on gerrni- nation of seed of this species (Table 1). Nonprimed seeds had similar germination percentages compared to primed seeds (data not shown). However, the interaction of temperature and stratification significantly affected the percentage of seed germination of A. hinckleyana (Table 1). Stratified seed held at 20C germinated slightly faster and consistently to a slightly higher percentage than seed that was not stratified. Thus, by day
$28,90 \%$ of stratified seed had germinated compared to only $83 \%$ of nonstratified seeds (difference significant at $\boldsymbol{P}=0.05$ ). All treatments germinated at $26 \mathrm{C}$ had $<3 \%$ germination for all treatments (data not shown).

Priming improved percent germination in two of three Aquilegia species. At day 28, the percentage of germination of primed, nonstratified seed of A. caerulea was similar to that of stratified seeds, indicating that priming was as effective as stratification. The opposite was true for seed germination of A. canadensis. Priming improved seed germination of stratified seeds for this species, but primed, nonstratified seeds did not equal stratified seed germination by termination of the experiment. Priming had no effect on seed germination of $A$. hinckleyana.

The genus Aquilegia belongs to the Ranunculaceae. Seeds in this family generally have small, undeveloped rudimentary embryos that must mature or after-ripen before they can germinate (Atwater, 1980; Ellis et al., 1985a). The primary block to embryo development and germination is the presence of inhibitors, -probably abscisic acid (ABA), in the endosperm that surrounds the embryo. The inhibitors must be leached out, neutralized, or blocked before after-ripening can occur (Atwater, 1980; Ellis et al., 1985a). After-ripening is normally accomplished in two ways: 1) seeds are kept in dry storage for 2 to 3 months at 25 to $30 \mathrm{C}$ (De Klerk, 1986) or 2) seeds are stratified in moist media at 3 to $15 \mathrm{C}$ for 2 to 4 weeks (Atwater, 1980; Ellis et al., 1985b). Priming may have functioned as a leachate of growth inhibitors (Heydecker and Coolbear, 1977), enabling treated seed to begin the pregermination processes earlier than nonprimed seed, but it did not act as a substitute for stratification in A. canadensis and A. hinckleyana.

The effect of priming duration also varied among species. As priming duration increased, germination decreased for A. canadensis. In contrast, ,A. caerulea seed germination was increased with increased priming duration. The decline in germination with increased duration of priming treatment for A. canadensis is consistent with previous studies on the effects of drying back seeds (after priming and before germinating) on germination responses (Heydecker and Gibbons, 1978). Studying celery (Apium graveoleus L.) seeds, which also exhibit thermodormancy responses, the seeds completely dried back that were primed for the longest period had a significant decrease in germination. This decrease was attributed to a rapid buildup of inhibitors. The fact that stratification appears to have re-energized the seeds of $A$. canadensis primed 48 and $72 \mathrm{~h}$ appears to enforce Heydecker's and Gibbon's conclusion that the reduction in germination is an inhibitor-induced response, and stratification (in these experiments) may have reversed the inhibitor effect.

For A. canadensis and A. hinckleyana, germination was greatly influenced by stratification and germination temperature. Stratified seed had consistently higher and faster germination at 20C than at 26C. Cantliffe's 
(1984) studies on the effects of priming on induced thermal (or thermo-) dormancy in lettuce seeds showed that priming is capable of overcoming the effects of thermodormancy at higher temperatures. Clearly, that was not the case in our experiment for seeds of A. hinckleyana and A. canadensis. The results of these experiments indicate that seeds either died or the higher germination temperature caused an induced, thermal dormant response in seeds that were already beginning to germinate. In fact, stratified seeds were the most sensitive to temperature, with the primed and nonprimed stratified seeds showing the greatest reductions in germination at 26C. Partially after-ripened apple seeds stratified at 5C for 6 days stopped germinating when temperatures were increased to 18C (Kozlowski, 1972). Valdes and Bradford (1987) indicated that even though priming promotes pregerminative processes in seeds, higher temperatures are still capable of stopping germination by inhibiting radicle extension. Aquilegia caerulea appeared to be less sensitive to the germination temperature, since there were no significant differences in germination between treated and nontreated seeds at 20 and 26C.

The results described above indicate that priming can have varying effects on germination of similar species. For less sensitive species, priming may be a viable alternative to stratification. For more sensitive species, priming alone does not appear to be a substitute for stratification and does not appear to overcome thermodormancy of these species at higher germination temperatures. Priming, coupled with stratification, may enhance the germination performance of seeds for some species, but again, the priming duration may vary between species.

\section{Literature Cited}

Atwater, B.R. 1980. Germination, dormancy, and morphology of the seeds of herbaceous ornamental plants. Seed. Sci. Technol. 8:523-573.

Ball, V. (ed.). 1985. Ball redbook: Greenhouse growing. 14th ed. Reston Publishing Co., Reston, Va.

Bradford, K.J. 1986. Manipulation of seed water relations via osmotic priming to improve germination under stress conditions. HortScience 21(5):1105-1111.

Brocklehurst, P.A. and J. Dearman. 1983. Interactions between seed priming treatments and nine seed lots of carrot, celery, and onion. II. Seedling emergence and plant growth. Ann. Appl. Biol. 102:585-593.

Cantliffe, D., J.M. Fischer, and T.A. Neil, 1984. Mechanism of seed priming in circumventing thermodormancy in lettuce. Plant Physiol. 75:290-294.

De Klerk, G.J. 1986. Advantages and detrimental effects of osmotic pre-sowing treatment on the germination of Agrostemma githago seeds. J. Expt. Bet. 37(179):765-774.

Ellis, R. H., T. D.' Hong, and E.H. Roberts. 1985a. Handbook of seed technology for genebanks, no. 2, vol. 1. Principles and methodology. Dept. of Agr. Hort., Univ. of Reading, U.K.

Ellis, R. H., T.D. Hong, and E.H. Roberts. 1985b. Handbook of seed technology for genebanks. no. 3 , vol. II. Compendium of specific germination information and test recommendations.
Dept. of Agr. Hort., Univ. of Reading, U.K. Heydecker, W. and P. Coolbear. 1977. Seed treatments for improved performance: Survey and attempted prognosis. Seed Sci. Technol 5:353425.

Heydecker, W. and B.M. Gibbons. 1978. The 'priming' of seeds. Acta Hort. 83:213-223.

Kozlowski, T.T. 1972. Seed biology. vol 3. Academic, New York.

Phillips, H.R. 1985. Growing and propagating wild flowers. Univ. of North Carolina Press, Chapel Hill.

Samfield, D. M., J.M. Zajicek, and B.G. Cobb. 1990. Germination of Coreopsis lanceolata and
Echinacea purpurea seeds following priming and storage. HortScience 25:1605-1606.

Samfield, D. M., J.M. Zajicek, and B.G. Cobb. 1991. Rate and uniformity of herbaceous perennial seed germination and emergence as affected by priming. J. Amer. Soc. Hort. Sci. 116:10-13.

Steele, R.G.D. and J.H. Torrie. 1980. Principles and practices of statistics. McGraw Hill, New York.

Valdes, V. and K.J. Bradford. 1987. Effect of seed coating and osmotic priming on the germination of lettuce seeds. J. Amer. Soc. Hort Sci. 112(1):153-156 